\title{
Pesquisa de aglutininas, antígeno de leptospiras e apoptose em rim de suínos naturalmente infectados por Leptospira spp. ${ }^{1}$
}

\author{
Larissa M.F. Gonçalves ${ }^{2}$, Ana Lys B.B. Mineiro ${ }^{3}$, Sônia M. de Carvalho ${ }^{2}$, Ângela P. \\ Campos $^{2}$, Luanna S. de Melo Evangelista ${ }^{4}$, Flaviane A. Pinho ${ }^{2}$, Élvio C. Moreira ${ }^{5}$ \\ e Francisco A.L. Costa ${ }^{3 *}$
}

\begin{abstract}
Gonçalves L.M.F., Mineiro A.L.B.B., Carvalho S.M., Campos A.P., Evangelista L.S.M., Pinho F.A., Silva S.M.M.S. \& Costa F.A.L. 2011. [Search agglutinins, leptospires antigen and apoptosis in the kidney of swine naturally infected with Leptospira spp.] Pesquisa de aglutininas, antígeno de leptospiras e apoptose em rim de suínos naturalmente infectados por Leptospira spp. Pesquisa Veterinária Brasileira 31(7):561-568. Setor de Patologia Animal, Departamento de Clínica e Cirurgia Veterinária, Centro de Ciências Agrárias, Universidade Federal do Piauí, Campus Agrícola da Socopo s/n. Teresina, PI 64.049-550, Brazil. E-mail:fassisle@gmail.com

Serum and kidney of 75 mixed bred swine (no definite breed) reared in an extensive system and slaughtered in Timon (state of Maranhão) and Teresina (state of Piauí), Brazil, two cities separated from each other by the Parnaiba River, and 75 crossbred swine from a confinement rearing system, sired by Landrace, Large White and/or Duroc, were used in this study. From the 150 analyzed samples for the microscopic agglutination test (MAT), seven were reagents and the serovar Icterohaemorrhagiae $(42.86 \%)$ was the most frequent. A comparison between both systems to verify a predisposition to Leptospira spp. infection showed that susceptibility was greater in extensively reared animals than in those bred in confinement $(\chi 2$ test, $p<0.05)$. Inflammatory infiltrates covered an average area larger in the seropositive revealing a significant difference for the seronegative animals ( $\mathrm{p}<0.05$, Mann-Whitney U-Test). Morphometric analysis showed Leptospira spp. and antigen labeling in seropositive animals only $(p<0.05$, Mann-Whitney U-test). Apoptosis in tubular epithelial cells was significantly more evident in the infected animals compared to uninfected. The rearing system and environment conditions are an important factor in the susceptibility of swine to Leptospira spp. infection. An eventual association of leptospira antigen and apoptotic cells suggests a probable mechanism of renal injury at leptospirosis.
\end{abstract}

INDEX TERMS: Leptospirosis, immunohistochemistry, kidney, swine.

RESUMO.- Soro e rim de 75 suínos mestiços sem raça definida, criados em sistema extensivo e abatidos em Timon (MA) e Teresina (Piauí), Brasil, duas cidades separadas pelo Rio Parnaíba e 75 suínos mestiços de um sistema de criação em confinamento, filhos de Landrace, Large White e/ ou Duroc foram utilizados neste estudo. Das 150 amostras

\footnotetext{
${ }^{1}$ Recebido em 7 de dezembro de 2010.

Aceito para publicação em 4 de março de 2011.

${ }^{2}$ Pós-Graduanda em Ciência Animal, Universidade Federal do Piauí (UFPI), Campus Agrícola da Socopo s/n, Teresina, PI 64049-550, Brasil.

${ }^{3}$ Departamento de Clínica e Cirurgia Veterinária, Centro de Ciências Agrárias, UFPI, Campus Agrícola da Socopo s/n, Teresina, PI. *Autor para correspondência: fassisle@gmail.com

${ }^{4}$ Departamento de Medicina Veterinária Preventiva, Escola de Veterinária, Universidade Federal de Minas Gerais, Av. Antônio Carlos 6627, Cx. Postal 567, Campus da UFMG, Belo Horizonte, MG 30123-970, Brasil.
}

analisadas pela prova de Soroaglutinação Microscópica (SAM), sete foram reagentes e o sorovar Icterohaemorrhagiae $(42,86 \%)$ foi o mais frequente. Uma comparação entre os dois sistemas para examinar uma predisposição para infecção para Leptospira spp. mostrou que a suscetibilidade foi maior nos animais criados extensivamente do que naqueles criados em confinamento (teste $\chi^{2}, \mathrm{p}<0,05$ ). A presença de infiltrado inflamatório foi significantemente maior nos animais soropositivos comparados aos soronegativos ( $\mathrm{p}<0,05$, Teste U de Mann-Whitney). A análise morfométrica mostrou Leptospira spp. e o antígeno de leptospira apenas nos animais soropositivos ( $p<0,05$, teste de U de MannWhitney). Apoptose em células epiteliais tubulares foi significantemente mais evidente nos animais infectados comparados aos não infectados $(\mathrm{p}<0,05$, Teste U de MannWhitney). Uma eventual associação de antígeno de Leptos- 
pira e células epiteliais em apoptose sugere um provável mecanismo de lesão renal na leptospirose suína.

TERMOS DE INDEXAÇÃO: Leptospirose, imunoistoquímica, rim, suíno.

\section{INTRODUÇÃO}

As leptospiroses são doenças zoonóticas de ampla distribuição geográfica que acometem os animais domésticos, silvestres e o homem. Os animais são considerados hospedeiros primários, responsáveis pela persistência dos focos de infecção e os seres humanos hospedeiros terminais, pouco eficientes na perpetuação da mesma (Badke 2001).

Levantamentos sorológicos para o diagnóstico de infecção por leptospiras em suínos realizados no Brasil, revelaram percentual de 27,3\% em São Paulo (Langoni et al. 1995), 42,2\% no Rio Grande do Sul (Lima 1996), 64,2\% em Goiás (Souza 2000), 66,1\% no Rio de Janeiro (Ramos \& Lilenbaum 2002), 36,6\% em Botucatu (Shimabukuro et al. 2003) e $14,6 \%$ no Paraná (Hashimoto et al. 2008). Em outros países foram encontrados percentuais de 78\% nos EUA (Miller et al. 1990), 10,6\% na Espanha (Perea et al. 1994), 20\% na Austrália (Chapell 1998), 23\% no Vietnam (Boqvist et al. 2003) e 10\% na Tailândia (Niwetpathomwat et al. 2006).

Os principais sorovares diagnosticados em suínos no Brasil pelo teste de soroaglutinação microscópica (SAM) foram: Pomona, Grippotyphosa, Pyrogenes, Canícola, Icterohaemorrhagiae, Autumnalis, Ballum e Javanica (Soto et al. 2007). No entanto, a leptospirose em suínos ainda não foi diagnosticada nos estados do Piauí e Maranhão.

Nos estados do Piauí e Maranhão vários sistemas de criação de suínos são adotados incluindo o extensivo, semi-extensivo, semi-confinado e confinado. No entanto, os sistemas extensivos e confinados são os dois mais utilizados. 0 sistema de criação extensivo é geralmente utilizado pela população de baixa renda. Este sistema é caracterizado pela falta de alimentação e instalações adequadas, bem como pelas más condições sanitárias. 0 sistema de criação confinado é utilizado para a criação de animais de raça melhorada, com controle de alimentação e boas condições sanitárias. Contudo, a vacinação contra a leptospirose não é praticada em nenhum desses sistemas de criação.

As lesões provocadas por Leptospira spp. são observadas, principalmente, nos rins onde as mesmas chegam por via hematógena e multiplicam-se provocando lesões túbulo-intersticiais, de onde são transportadas pela urina para o meio ambiente, em condições viáveis, para infectar outros animais e o homem (Scanziani et al. 1989, Yang et al. 2001).

A nefropatia causada pelas leptospiras tem sido estudada de modo mais consistente no homem (Sitprija et al. 1980), mas nos animais, especialmente em suínos naturalmente infectados, pouco se sabe sobre os padrões morfológicos e sobre a patogenia da lesão renal, visto que vários mecanismos estão envolvidos.

No homem e em hamsters infetados experimentalmente, a pesquisa de leptospiras pelo método de imunoperoxidase revelou a predominância de antígeno no interstício, no endotélio de vasos, no epitélio e lúmen dos túbulos contornados, no citoplasma de alguns macrófagos e próximo a vasos sanguíneos (Alves et al. 1989, Haanwinckel, et al. 2004).
Um mecanismo de lesão renal que vem sendo bastante estudado em vários processos patológicos é o fenômeno de morte por apoptose (Savill 1994, Wong et al. 2001). A morte celular por apoptose regula o número de células durante a indução e a resolução de injúria renal (Ortiz et al. 2000). A ocorrência de apoptose em rim de ovinos naturalmente infectados por Leptospira spp. já foi observada, sendo mais intensa na região medular em comparação à região cortical e parece ter ação primária sobre as células epiteliais tubulares (Carvalho 2005).

0 presente estudo teve como objetivo diagnosticar a infecção de suínos por Leptospira spp. nos estados do Piauí e Maranhão e avaliar a presença de antígeno de leptospira e apoptose em associação com as alterações renais.

\section{MATERIAL E MÉTODOS}

\section{Descrição da área de estudo}

Timon está localizada na mesorregião do leste do Maranhão e microrregião de Caxias, Brasil, ocupando uma área de $1886 \mathrm{~km}^{2}$. A cidade está a $69 \mathrm{~m}$ acima do nível do mar e situa-se $5^{\circ} 05^{\prime} 40^{\prime \prime}$ de latitude sul e $42^{\circ} 50^{\prime} 12^{\prime \prime}$ de longitude oeste. Tem um clima tropical megatérmico e sub-úmido do tipo seco. A precipitação anual é de cerca de 1.300 milímetros, mas a distribuição é irregular ao longo do ano. A estação chuvosa ocorre de dezembro a abril, quando concentra cerca de $85 \%$ das chuvas anuais. As temperaturas são altas o ano todo (média anual é de $27,5^{\circ} \mathrm{C}$ ). Os tipos de vegetação são classificados como: floresta mesófila tropical (floresta estacional com babaçu) e não-florestal semidecídua xeromorfa (Cerrado). A rede hidrográfica é constituída pelo rio Parnaíba e por seus afluentes. A bacia do Itapecuru constitui um divisor que se interpõe entre a Bacia do Parnaíba a leste e a Bacia do Mearim a oeste. Esta bacia situa-se numa zona de transição dos climas semi-áridos do interior do Nordeste para o clima úmido equatorial da Amazônia, onde são encontradas numerosas fontes de água (Alcântara 2004, SEBRAE 2009).

Teresina, capital do estado do Piauí, ocupa uma área de $176 \mathrm{~km}^{2}$, na confluência dos rios Parnaíba e Poti. Está a $72 \mathrm{~m}$ acima do nível do mar e situa-se a $05^{\circ} 05^{\prime}$ de latitude sul e $42^{\circ} 48^{\prime}$ de longitude oeste. 0 clima é tropical com temperatura média de $27^{\circ} \mathrm{C}$ e precipitação anual de $1.300 \mathrm{~mm}$. A vegetação predominante é constituída por gramíneas, arbustos esparsos, manga e babaçu. As áreas periurbanas são cobertas por florestas tropicais e terras cultivadas (Bastos \& Andrade Júnior 2000). As temperaturas variam pouco, às vezes ultrapassando $40^{\circ} \mathrm{C}$, sendo a mínima raramente inferior a $20^{\circ} \mathrm{C}$. Os meses mais frios (dezembro-abril) são também os mais chuvosos, quando chove cerca de $287 \mathrm{~mm}$. 0 mês mais seco é agosto, quando chove cerca de $13 \mathrm{~mm}$. A rede hidrográfica é constituída pelo rio Parnaíba e pela bacia do rio Poti. A parte ocidental da bacia é inserida em uma área de tensão ecológica. A parte oriental da bacia é inserido na caatinga. A caatinga domina a região semi-árida sul e leste do Piauí (Piauí 2009).

\section{Animais e diagnóstico sorológico da infecção por Leptospira spp.}

Foram utilizados 150 suínos de ambos os sexos, adultos, distribuídos em dois grupos: Grupo 1 constituído de 75 animais de raças indefinidas, criados extensivamente e abatidos em Timon-MA e Teresina-PI e o Grupo 2 constituído de 75 animais de criação confinada, mestiços de Landrace, Large White e/ou Duroc, mantidos e abatidos no Setor de Suínos do Departamento de Zootecnia do Centro de Ciências Agrárias da Universidade Federal do Piauí (UFPI), em Teresina, de setembro de 2007 a maio de 2008.

No momento do abate dos animais amostras de sangue foram colhidas durante a fase de sangria em tubos de $10 \mathrm{~mL}$ sem anticoa- 
gulante, para a realização da prova de soroaglutinação microscópica (SAM). 0 sangue foi centrifugado a $10.000 \mathrm{~g}$ por 10 minutos para a obtenção do soro; em seguida foi colocado em microtubos de $1,5 \mathrm{~mL}$ e posteriormente armazenado a $-20^{\circ} \mathrm{C}$ até a realização da prova de soroaglutinação.

O diagnóstico da infecção por Leptospira spp. foi realizado pela técnica de SAM, no Laboratório de Zoonoses do Departamento de Medicina Veterinária Preventiva da Escola de Veterinária da Universidade Federal de Minas Gerais. A técnica foi efetuada com coleção de antígenos vivos que incluiu 12 variantes sorológicas patogênicas de Leptospira interrogans sorovares Autumanalis, Bratislava, Canícola, Copenhageni, Grippotyphosa, Hardjoprajitno (CTG), Pomona e Pyrogenes; L. borgpetersenii sorovares Tarassovi, Hardjobovis e Ballum e L. inadai sorovar Icterohaemorrhagiae. A técnica foi realizada com apenas 12 sorovares por serem esses os mais freqüentes que infectam suínos no Brasil. Os sorovares com quatro a 14 dias de crescimento foram diluídos na proporção de 1:3 em PBS (Phosphate Bufferid Saline - solução salina tamponada com fosfato), pH 7,2. 0 critério adotado para o soro ser considerado como reagente foi de $50 \%$ de leptospiras aglutinadas por campo microscópico em aumento de 100 vezes. 0 sorovar registrado foi aquele que apresentou maior título, sendo as demais aglutinações consideradas reações cruzadas. As amostras positivas ao título inicial foram novamente diluídas sucessivamente na razão dois e testadas para o(s) sorovar(es) que reagiu(ram) anteriormente.

\section{Análise histopatológica do rim}

Após o abate dos animais foram colhidos fragmentos de rim das regiões cortical e medular, de aproximadamente $0,5 \mathrm{~cm}$ de espessura que foram fixados em formol neutro a $10 \%$ (formol tamponado) e em solução de Duboscq-Brasil por 60 minutos e posteriormente mantidos em formol tamponado até o processamento.

Os fragmentos de rim que foram fixados primeiramente em solução de Duboscq-Brasil e posteriormente mantidos em formol tamponado, foram corados com hematoxilina-eosina (H-E), ácido periódico de Schiff (PAS), tricrômico de Masson (Masson), ácido periódico prata metanamine (PAMS) e Warthin Starry. Os fragmentos fixados apenas em formol tamponado foram preparados em lâminas tratadas com adesivo Silane A174 (Pharmacia, USA) para aplicação da técnica de Imunoperoxidase.

\section{Detecção de antigeno de Leptospira spp. em tecido renal}

Para a detecção de antígeno de leptospira, os cortes de tecidos foram desparafinados em xilol e hidratados em concentrações decrescentes de álcool etílico; foram submetidos a bloqueio de peroxidase endógena com peróxido de hidrogênio $0,03 \%$, em metanol por 30 minutos no escuro e tratados em forno de microondas (Jedfrost: Brastemp, SP) potência máxima, em solução Tris-Hcl pH 1, sucessivamente por 10 e 5 minutos. Após lavagem com PBS os cortes foram incubados "overnight" em atmosfera úmida, na temperatura de $4^{\circ} \mathrm{C}$ com anticorpo policlonal de coelho anti-leptospiras (produzido no Laboratório de Patologia Animal do Departamento de Clínica e Cirurgia Veterinária da UFPI) na diluição de 1:200. No dia seguinte, a incubação com anticorpo secundário e a amplificação da reação foi realizada com o EnVision System (Dako Comporation Carpinteria CA, USA, código K4002) em atmosfera úmida, temperatura ambiente por 30 minutos. A revelação da reação foi feita com $0,3 \mathrm{mg} / \mathrm{ml}$ de 3,3'-diaminobenzidina (Sigma Chemical, USA) em PBS com 0,06\% de peróxido de hidrogênio e contra-coloração com hematoxilina de Harrys. Como controle positivo, foi utilizado tecido renal de ovino naturalmente infectado por Leptospira spp. e como controle negativo foi omitido o anticorpo primário.

0 anticorpo foi obtido de coelhas imunizadas contra leptospirose com vacina comercial inativada (Leptospiro-Vac), sorovares Hardjo, Icterohaemorragiae, Bratislava, Pomona e Wolffi, e testado em tecido renal parafinado de bovino naturalmente infectado por Leptospira spp., com o qual reagiu positivamente e em tecido renal parafinado de hamster não infectado, com o qual não houve reação positiva.

\section{Detecção de apoptose em tecido renal}

Apoptose foi detectada por meio do kit apopTag Peroxidase in situ (Chemicon International, Califórnia, USA, código S7101) segundo o protocolo recomendando pelo fabricante. Resumidamente a técnica consistiu na desparafinização dos cortes de tecido renal com xilol; posteriormente os cortes foram hidratados em concentrações decrescentes de álcool etílico. Em seguida, foram incubados com proteinase K (Invintrogen life Technologies, Califórnia, Sigma, Chemical, USA) $(20 \mu \mathrm{g} / \mathrm{ml})$, durante 15 minutos. 0 bloqueio de peroxidase endógena foi realizado com peróxido de hidrogênio a $0,03 \%$, por 5 minutos. Após lavagem das lâminas em PBS, foi feita incubação com Equilibration buffer (tampão de equilíbrio) por 10 segundos em temperatura ambiente. Os cortes foram então incubados em atmosfera úmida a $37^{\circ} \mathrm{C}$ com solução contendo Terminal Deoxinucleotidil Transferase (TdT) durante 60 minutos. Em seguida foi utilizada a solução tampão de parada da reação (stop/wash buffer) por 10 minutos. Após lavagem em PBS, foram incubados com conjugado anti-digoxigenina por 30 minutos e feita lavagem em PBS por 8 minutos. A revelação da reação foi realizada com solução de $0,3 \mathrm{mg} / \mathrm{ml}$ de 3,3'-diaminobenzidine tetrahidrocloride em PBS com 0,06\% de peróxido de hidrogênio e a contracoloração com hematoxilina de Harrys. As lâminas foram montadas com entelan para exame em microscópio de luz. Como controle positivo foi utilizado tecido mamário de uma fêmea normal de roedor em que apoptose intensa ocorre 3 a 5 dias após o desmame. Como controle negativo foi omitida a enzima TdT na reação, conforme recomendação do fabricante.

\section{Morfometria}

Cortes de rim de aproximadamente 4 a $5 \mu \mathrm{m}$ de espessura, corados por HE e imunoperoxidase, foram submetidos a análise morfométrica utilizando analisador de imagem computadorizada Leica Qwin D-1000, versão 4.1 (versão 4.1: Cambridge, UK) do Setor de Patologia Animal/BIOLAI, do CCA/UFPI. Foram capturados de 20 a 50 campos por corte de tecido renal de cada animal, incluindo as regiões cortical, córtico-medular e medular. Desse total foram mensuradas as áreas correspondentes à presença de células inflamatórias, antígeno de leptospira e células em apoptose, em comparação à área total de cada campo.

\section{Análise estatística}

Para verificar a associação entre a ocorrência da doença e os manejos (confinado e extensivo), foi utilizado teste de Qui-Quadrado. A intensidade das lesões foi classificada semi-quantitativamente, em escores, numa escala de 0 a 5, onde 0 = normal, 1 = mínima; 2 = média; 3 = moderada; 4 = moderadamente severa; 5 = severa (Pirani 1994). Os resultados quantitativos foram analisados no programa estatístico Sigma Stat, por testes não paramétricos: a) método de Kruskal-Wallis para análise de variância. Havendo diferença significante, aplicou-se o teste de Dunn para comparação múltipla de grupos; b) Teste U de Mann-Whitney para comparação entre dois grupos. Adotou-se o nível de significância de 5\%.

\section{RESULTADOS}

\section{Diagnóstico sorológico}

Do total de 150 amostras de soros analisadas pela prova de SAM sete (seis de Timon-MA e um de Teresina-PI) foram reagentes para um ou mais sorovares de Leptospira spp., resultando em uma soropositividade de 4,7\%. 
Dentre os animais reagentes três apresentaram reação para um único sorovar, sendo o de maior ocorrência o sorovar Icterohaemorrhagiae (3/7). Três animais apresentaram títulos de anticorpos de 100, um animal apresentou título de 400 , um de 800, um de 6.400 e outro de 51.200.

Os animais que reagiram ao sorovar Icterohaemorrhagiae corresponderam a $42,86 \%$ (3/7), seguidos dos sorovares Canícola, 14,28\% (1/7), Autumnalis, 14,28\% (1/7), Pomona, $14,28 \%$ (1/7) e Pyrogenes, $14,28 \%$ (1/7).

A comparação entre os dois sistemas de criação quanto à predisposição para contrair infecção por Leptospira spp., revelou que a suscetibilidade é maior nos animais criados extensivamente do que nos animais de criação confinada (Tes-

Quadro 1. Comparação entre dois sistemas de criação quanto à predisposição para contrair infecção por Leptospira spp. Teste qui-quadrado $\left(\chi^{2}\right)$ sobre a tabela de contingência $2 \times 2$

\begin{tabular}{cccc}
\hline Animais & Criação extensiva & Criação confinada & Total \\
\hline Positivos & 7 & 0 & 7 \\
Negativos & 68 & 75 & 143 \\
Total & 75 & 75 & 150
\end{tabular}

$\mathrm{p}=0,02$.

te $\chi^{2}, \mathrm{p}<0,05$ ) (Quadro 1).

\section{Alterações renais histopatológicas}

Para análise das lesões renais 14 suínos foram utilizados, sete sorologicamente positivos e sete sorologicamente negativos (grupo controle). Dos sete animais soropositivos todos apresentaram alterações túbulo-intersticiais. Nefrite intersticial foi observada em todos os animais soropositivos caracterizada pela presença predominante de linfócitos e macrófagos (Fig.1). A lesão localizava-se principalmente na região cortical, mas, também, na região córtico-medular e medular de distribuição focal, perivascular, periglomerular e peritubular, com intensidade variando de mínima a moderada. A presença de infiltrado inflamatório era significantemente maior nos animais soropositivos comparados aos soronegativos ( $\mathrm{p}<0,05$, Teste U de Mann-Whitney) (Fig.2). Não houve diferença significante quanto ao infiltrado inflamatório entre as regiões cortical, córtico-medular e medular nos animais

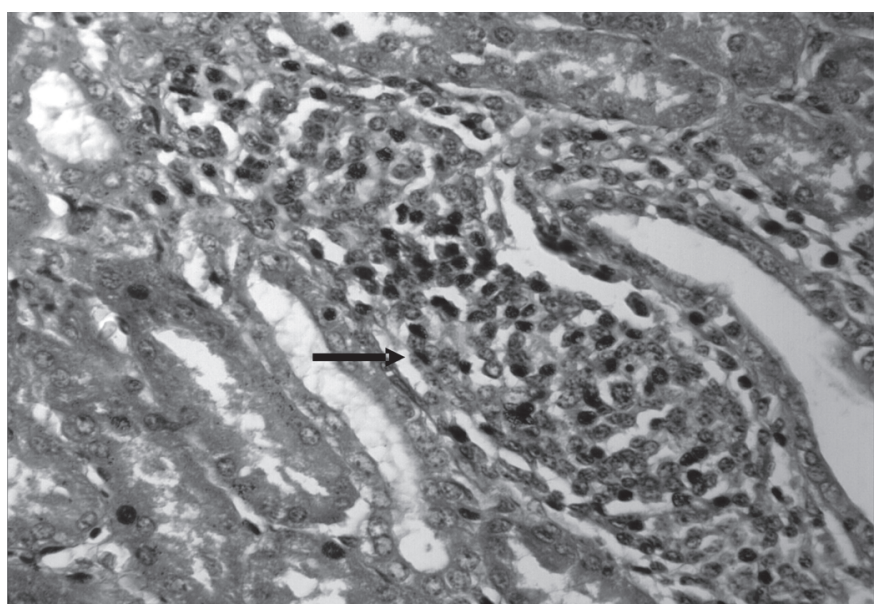

Fig.1. Infiltrado inflamatório mononuclear (seta) no rim de suíno naturalmente infectado com Leptospira spp. H-E, Barra $=25 \mu \mathrm{m}$.

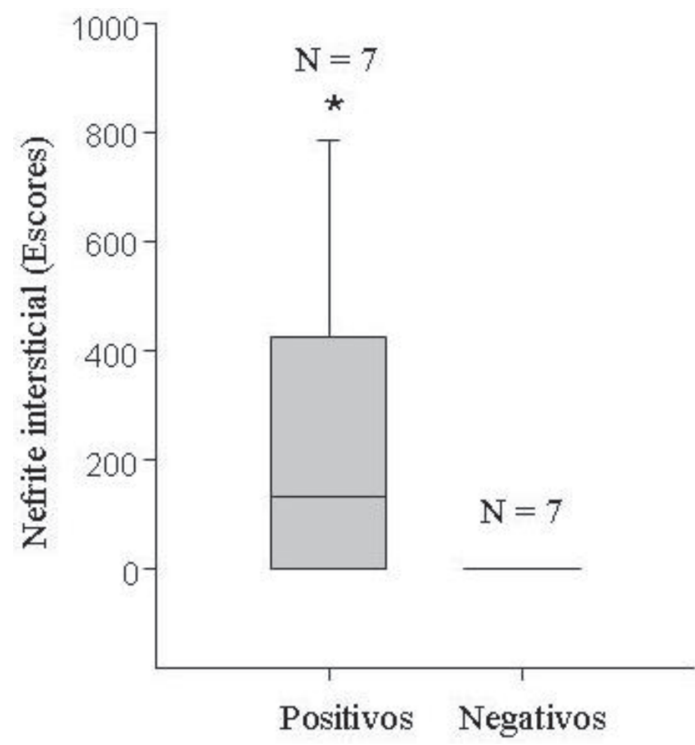

Fig.2. Análise quantitativa da intensidade da nefrite intersticial (percentual médio dos escores entre 25 e 75) em suínos infectados com Leptospira spp. $\mathrm{N}=$ múmero de animais por grupo. ${ }^{*} \mathrm{p}<0.005$, Mann-Whitney.

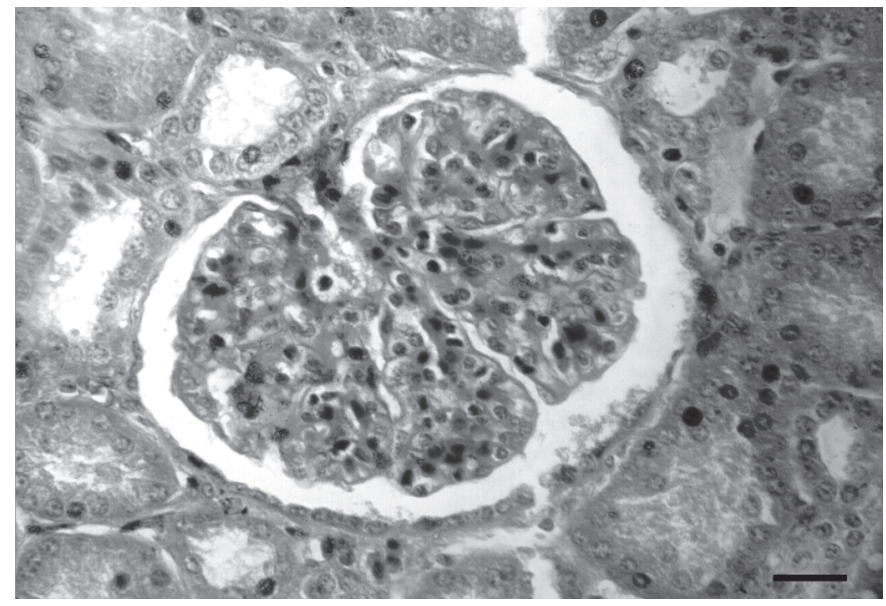

Fig.3. Hipercelularidade de células mesangiais e lobulação de glomérulos no rim de suíno naturalmente infectado por Leptospira spp. H-E, Barra $=25 \mu \mathrm{m}$.

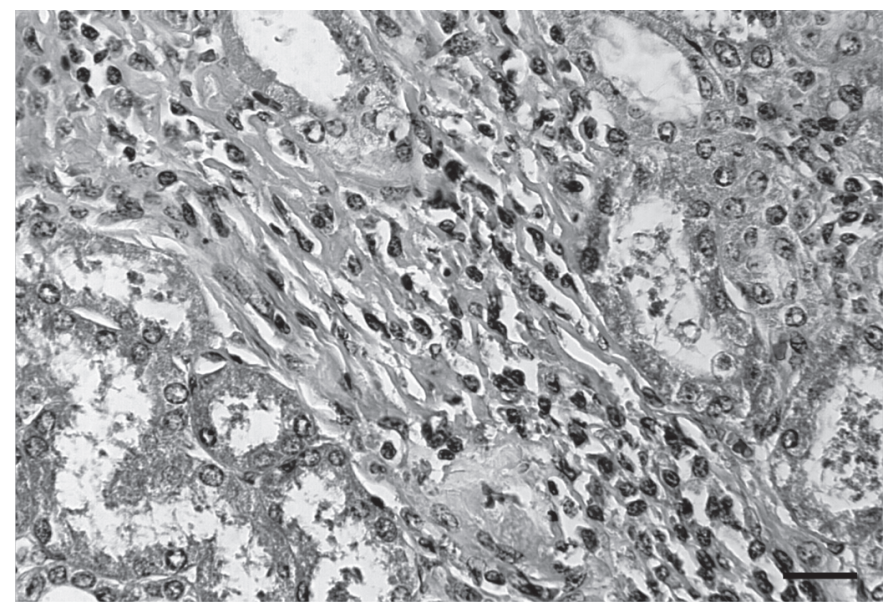

Fig.4. Fibrose intertubular (seta) no rim de suíno naturalmente infectado por Leptospira spp. Masson, Barra $=25 \mu \mathrm{m}$. 
soropositivos. Em glomérulos foi observada hipercelularidade focal de células mesangiais em quatro animais. Em dois casos o tufo glomerular apresentava-se lobulado (Fig.3), com espessamento da membrana basal do capilar glomerular e presença de material protéico na cápsula de Bowman de um animal. Em outro animal foi observado crescente celular. Nos túbulos constatou-se atrofia focal em quatro animais e fibrose renal (Fig.4) em cinco. Pela coloração Warthin Starry, não foi observado presença de leptospiras.

\section{Detecção de antígeno de Leptospira}

Embora a prova de SAM tenha revelado apenas sete animais sororeagentes e, portanto, 143 animais soronegativos, quando foi realizada a técnica de imunoistoquímica em 23 desses animais, selecionados ao acaso, e dos sete sororeagentes, constatou-se que os 30 foram positivos para antígeno de Leptospira spp. (Fig.5) e em um animal foi observado a presença de Leptospira spp. em túbulo renal (Fig.6). Contudo deve ser salientado que o parâmetro básico, tomado como referência, para a definição de animais infectados e não infectados foi a prova de SAM.

A análise morfométrica realizada em tecido renal de 14 animais, sendo 7 soropositivos e 7 soronegativos, revelou marca-

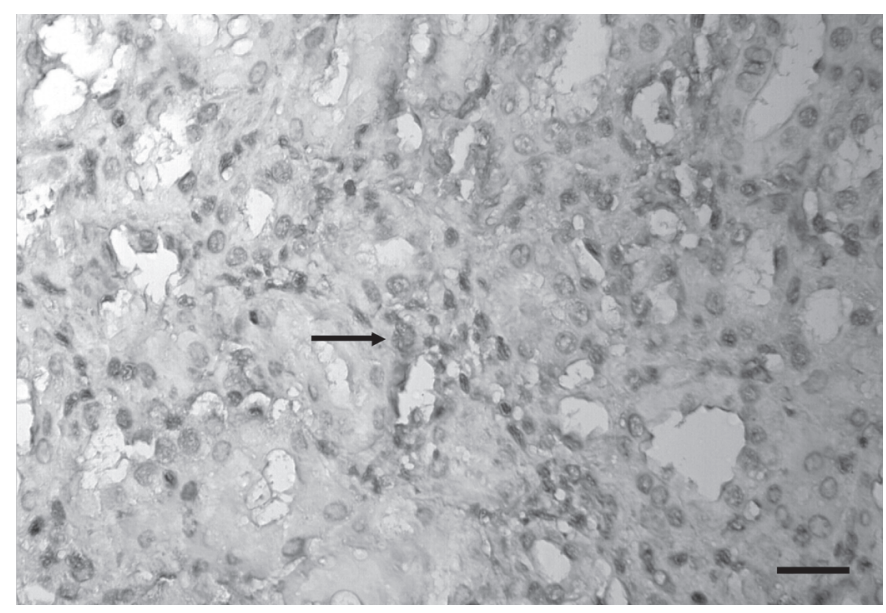

Fig.5. Antígeno de Leptospira em células epiteliais (seta) no rim de suíno naturalmente infectado por Leptospira spp. Immunoperoxidase, Barra $=25 \mu \mathrm{m}$.

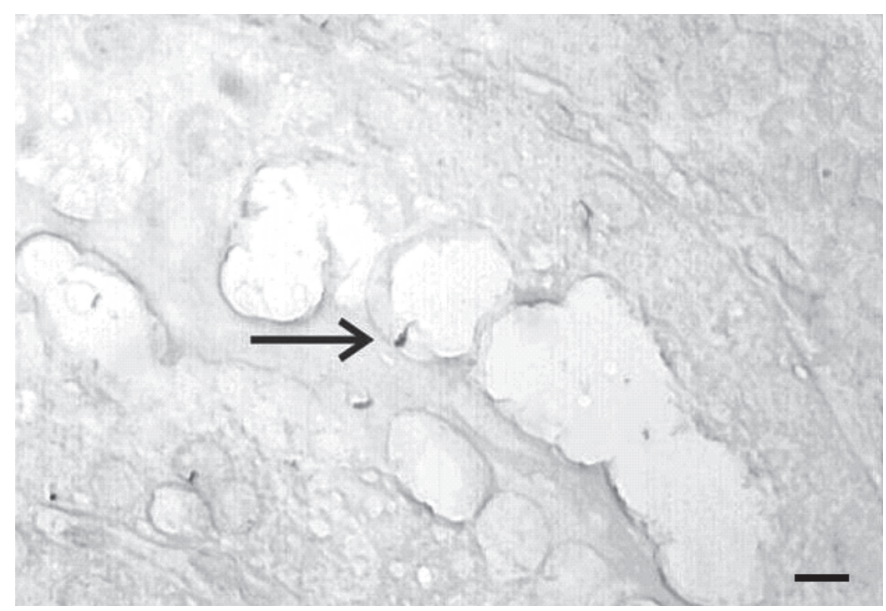

Fig.6. Leptospira spp. em túbulo urinífero (seta) em suíno naturalmente infectado. Imunoperoxidase, Barra $=10 \mu \mathrm{m}$.

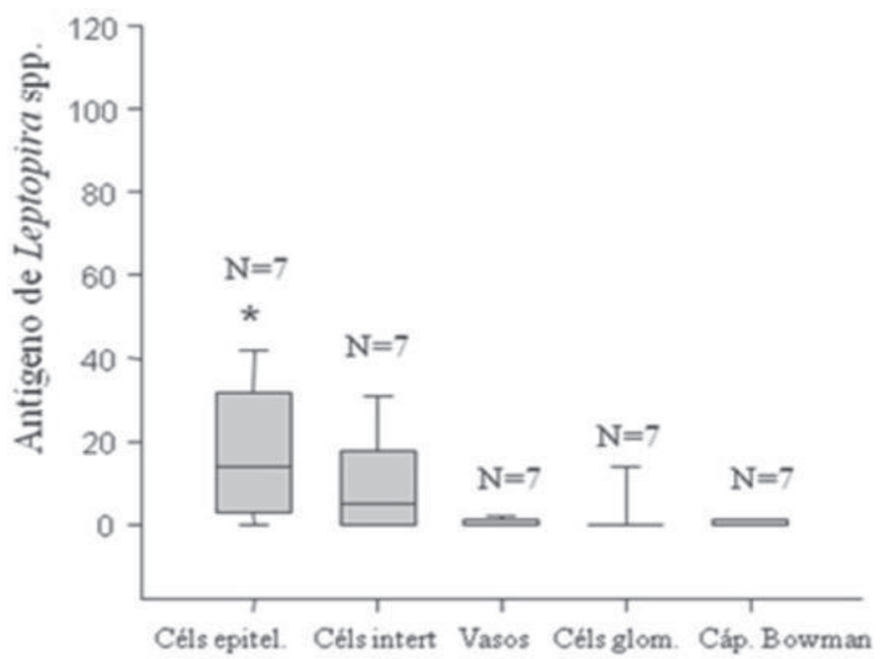

Fig.7. Análise quantitativa da intensidade de antígeno de Leptospira spp. (média dos escores e intervalo entre 25 e 75 por cento) em suínos infectados. $\mathrm{N}=$ número de animais por grupo. ${ }^{*} \mathrm{p}<0.005$, Kruskal Wallis and Dunn.

ção de antígeno apenas nos animais soropositivos, com diferença significante quando comparado aos soronegativos ( $\mathrm{p}<0,05$, Teste $\mathrm{U}$ de Mann-Whitney). 0 antígeno apresentavase em maior quantidade na região cortical em comparação às regiões córtico-medular e medular $(\mathrm{p}<0,05$, Teste de KruskalWallis e Dunn) nos animais soropositivos. A presença de antígeno de leptospira foi significantemente maior nas células epiteliais e intersticiais quando comparada aos vasos, células glomerulares e cápsula de Bowman ( $\mathrm{p}<0,05$, Teste de KruskalWallis e de Dunn) (Fig.7).

\section{Detecção de apoptose}

A verificação de células em apoptose foi realizada nos mesmos animais estudos na histopalogia, sete animais soropositivos e em quatro soronegativos. Apoptose estava presente em células epiteliais dos túbulos nos sete animais soropositivos em intensidade mínima (Fig.8). As células apoptóticas foram claramente marcadas, apresentando núcleo retraído de coloração marrom pela técnica de imunois-

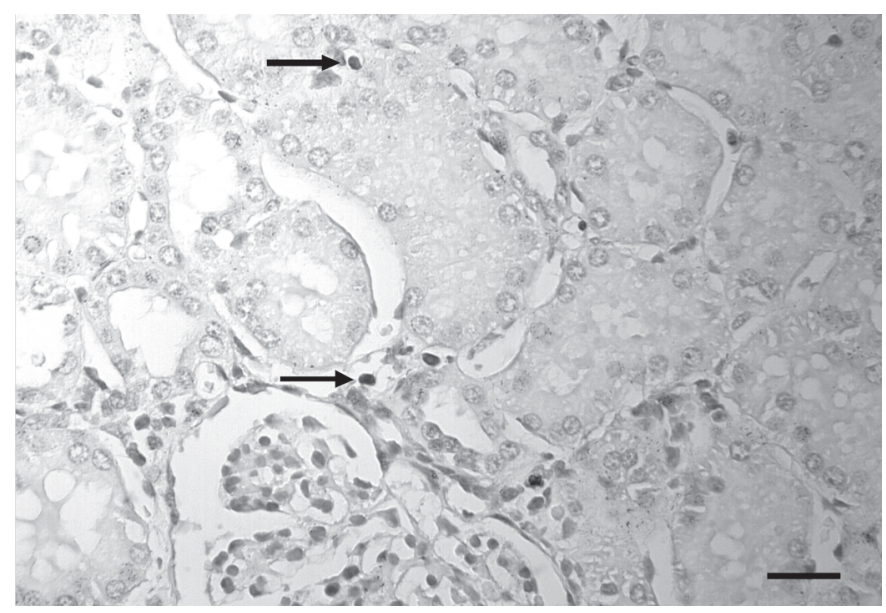

Fig.8. Células em apoptose (setas) no rim de suíno naturalmente infectado com Leptospira spp. Immunoperoxidase, Barra = $25 \mu \mathrm{m}$. 


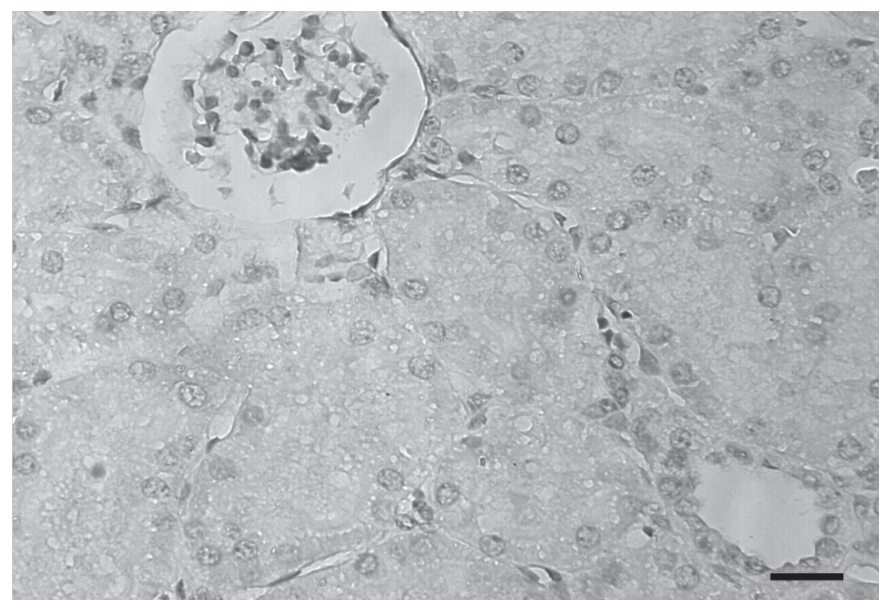

Fig.9. Rim de suíno soronegativo (Controle). Immunoperoxidase, Barra $=25 \mu \mathrm{m}$.

toquímica empregada. Não foi observada apoptose nos animais controles (Fig.9). Quando comparamos os dois grupos de animais na presença de apoptose, verificou-se que existia marcação significantemente maior nos animais soropositivos em relação aos soronegativos $(\mathrm{p}<0,05$, Teste $U$ de Mann-Whitney). 0 controle positivo da reação, realizado com tecido mamário de uma fêmea normal de roedor mostrou marcação positiva esperada.

\section{DISCUSSÃO}

A pesquisa de aglutininas anti-leptospiras em animais de abatedouro não constitui um procedimento adequado para a determinação da prevalência da doença em uma região ou cidade, no entanto, ela permite o registro da infecção bem como dos sorovares de Leptospira spp. que estão ocorrendo na região de origem dos animais. No presente trabalho sete $(4,7 \%)$ de um total de 150 suínos oriundos de Teresina-PI e Timon-MA e arredores, apresentaram anticorpos antileptospiras. Outros estudos registraram percentual de 7,7\% em suínos de Viçosa e Ponte Nova, MG (Faria et al. 1989), $55,8 \%$ no Rio Grande do Sul (Oliveira et al. 1995), 27,3\% em São Paulo (Langoni, Cabral \& Jacobi 1995), 65,2\% em Goiás (Souza 2000), 26,6\% no Ceará e $45 \%$ em Pernambuco (Favero et al. 2002) e 36,6\% na região de Botucatu, SP (Shimabukuro et al. 2003).

As evidências sorológicas encontradas neste estudo indicaram maior importância para os sorovares patogênicos Icterohaemorrhagiae $(42,86 \%)$, Autumnalis $(14,28 \%)$, Canícola (14,28\%), Pomona (14,28\%) e Pyrogenes (14,28\%), presentes em sete animais soropositivos. 0 sorovar Icterohaemorrhagiae foi o de maior ocorrência. Resultados similares ou percentualmente superiores foram encontrados em outros estudos (Langoni, Cabral \& Jacobi 1995, Oliveira et al. 1995, Souza 2000, Favero et al. 2002, Shimabukuro et al. 2003) revelando que o diagnóstico de sorovares infectantes para suínos varia também na dependência da região.

Os resultados deste trabalho revelaram que existe uma maior predisposição dos animais criados extensivamente para contrair infecção por Leptospira spp. do que os animais de criação confinada, o que tem sido confirmado também em estudos de sistema de criação de animais ao ar livre (SISCAL)
(Osava et al. (2010). A maior predisposição dos animais criados extensivamente, provavelmente, decorra das condições higiênico-sanitárias precárias adotadas na criação extensiva, onde os animais são expostos a uma grande variedade de patógenos e para os quais não recebe nenhum tipo de imunização, especialmente para leptospiras. Este tipo de sistema de criação favorece o contato dos animais com fontes de infecção de leptospiras bem como materiais contaminados.

Dos 14 animais incluídos na casuística das alterações histopatológicas sete (50\%) apresentaram alterações renais. As lesões localizavam-se nas três regiões, mas, com maior intensidade na região cortical. Estudos mostraram que o local preferencial da lesão renal na leptospirose é no espaço túbulointersticial, principalmente nos túbulos proximais (Sitprija et al. 1980, Barnett et al. 1999), locais onde a leptospira fica aderida e libera toxinas que danificam as células epiteliais (Alves et al. 1987).

Verificou-se que lesões túbulo-intersticiais como nefrite intersticial e atrofia tubular, estavam presentes em todos os animais soropositivos (100\%), mas não estavam nos animais soronegativos. Este é um dado importante, pois confirma a relação entre a infecção por leptospiras com a injúria renal em suínos aparentemente sadios. Observou-se também a presença de fibrose renal em cinco animais soropositivos, sendo que a intensidade variou de mínima a moderada, concordando com algumas pesquisas já realizadas (Hamir et al. 2001, Martínez et al. 2005). A técnica de Warthin-Starry não possibilitou a visualização de leptospiras, demonstrando que esta técnica não apresenta grande sensibilidade quando comparada com a imunoistoquímica, como observado por Scanziani et al. (1989), Silva et al. (2005) e Saglam et al. (2008).

A técnica de imunoistoquímica é uma das mais sensíveis para detecção de Leptospira spp. em tecido renal. Pela coloração de imunoperoxidase foi observada a presença de Leptospira spp. em um animal, aderida às células epiteliais tubulares. Antígeno foi observado em maior intensidade nas células epiteliais e intersticiais quando comparado a outras estruturas renais, o que sugere que estes sejam os locais preferenciais de ação das leptospiras sobre o rim, corroborando outras pesquisas realizadas em humanos, hamsters e bovinos (Alves et AC. 1989, Haanwinckel et al. 2004, Silva et al. 2005). A presença de antígeno de leptospira em vasos foi encontrada em intensidade mínima o que difere de outros resultados em que a presença de antígeno era mais intensa em vasos dilatados (Alves et al. 1989). Além disso, os resultados desta pesquisa evidenciaram antígeno de leptospira em intensidade significantemente maior em células glomerulares dos animais infectados quando comparados aos não infectados $(p<0,05)$, demonstrando que os glomérulos também são comprometidos no curso da infecção em suíno.

A detecção de apoptose neste estudo foi significantemente maior nos animais soropositivos quando comparados aos soronegativos $(\mathrm{p}<0,05)$. Apoptose estava presente no local preferencial de colonização das leptospiras, as células epiteliais tubulares (Barnett et al. 1999). Porém, apesar da intensidade da apoptose ter sido mínima, foi suficiente para distinguir apoptose fisiológica (Sorenson 1998) da apoptose como conseqüência do processo patológico renal presente nos animais 
infectados. Deve ser levado em consideração que em animais infectados por sorovares já adaptados, como no caso do suíno no presente estudo (Oliveira 1999), é de se esperar que apoptose ocorra em intensidade mínima como foi observado, muito embora acima do limiar fisiológico em decorrência do processo de adaptação, uma vez que as reações gerais do animal frente a esse tipo de infecção manifestam-se de forma discreta (Shimabukuro et al. 2003).

Em pesquisa realizada com rim de ovinos infectados naturalmente por Leptospira spp., foi observado que a intensidade de apoptose variou de mínima a severa, com presença de células apoptóticas em quantidade significantemente maior nos animais soropositivos quando comparado aos soronegativos (Carvalho 2005). Esses resultados, apesar de diferirem quanto à intensidade, são similares aos encontrados no presente estudo. Deve-se salientar que apoptose estava presente apenas em células epiteliais dos túbulos da região cortical, enquanto em ovinos estava presente em quantidade significantemente maior em células epiteliais de túbulos da região medular, comparado às células epiteliais da região cortical. Esses dados sugerem que apoptose participa do processo de injúria de células epiteliais renais na infecção por leptospiras em suínos em intensidade menor que em ovinos.

Os resultados deste estudo demonstraram a infecção por Leptospira spp. em suínos das cidades de Teresina-PI e TimonMA, com maior ocorrência do sorovar Icterohaemorrhagiae. Suínos de criação extensiva estavam mais susceptíveis à infecção que os suínos de criação confinada. Uma eventual associação da presença de antígeno e células em apoptose, em rim de suínos soropositivos, sugere um provável mecanismo de injúria renal na leptospirose.

Agradecimentos.- Ao Conselho Nacional de Desenvolvimento Científico e Tecnológico (CNPq), pela concessão de bolsa de mestrado.

\section{REFERÊNCIAS}

Alcântara E.H. 2004. Caracterização da bacia hidrográfica do rio Itapecuru, Maranhão, Brasil. Caminhos de Geografia 7:97-113. Disponível em <www.ig.ufu.br/caminhos_de_geografia.html> Acesso em 21 set. 2009.

Alves V.A., Vianna M.R., Yasuda P.H. \& De Brito P. 1987. Detection of leptospiral antigen in the human liver and kidney using an immunoperoxidase staining procedure. J. Pathol. 151:125-131.

Alves V.A.F., Siqueira A.S. \& Pestana C.B. 1989. Patologia da leptospirose. Análise crítica dos aspectos morfológicos e imuno-histoquímicos relevantes para a compreensão da patogenia. Revta Inst. Adolfo Lutz 49:7580.

Badke M.R.T. 2001. Leptospirose. Disponível em<http://www.cnpsa. embrapa.br/abraves-sc/pdf/Memorias2001/1_manoelrenato.pdf> Acessado em 2 dez. 2008.

Barnett J.K., Barnett D., Bolin C.A., Summers T.A., Wagar E.A. \& Cheville N.F. 1999. Expression and distribution of leptospiral outer membrane components during renal infection of ramsters. Infect. Immun. 67:853861.

Bastos E.A. \& Andrade Júnior A.S. 2000. Dados agrometereológicos para o município de Teresina-PI (1980-1999). Embrapa Meio-Norte, Teresina, p.25.

Boqvist S., Montgomery J.M., Hurst M., Ho Thi Viet Thu, Olsson Engvall E., Gunnarsson A. \& Magnusson U. 2003. Leptospira in slaughtered fattening pigs in southern Vietnam: Presence of the bacteria in the kidneys and association with morphological findings. Vet. Microbiol. 93:361-368.

Carvalho S.M. 2005. Patologia e patogenia da nefropatia na infecção por leptospiras em ovinos. Dissertação de Mestrado em Ciência Animal, Cen- tro de Ciências Agrárias, Universidade Federal do Piauí, Teresina, PI. $64 \mathrm{p}$.

Chapell R.J. 1998. Prevalence and geographic origin of pigs with serological evidence of infection with Leptospira interrogans serovar Pomona slaughtered in abattoir in Victória, Australia. Vet. Microbiol. 62:235-242.

Faria E.J., Ribeiro M.F.B., Santos J.L., Dale R. \& Salcedo J.H.P. 1989. Frequência de aglutininas anti-leptospiras em soros sanguíneos de suínos das microregiões de Viçosa e Ponte Nova-MG. Arq. Bras. Med. Vet. Zootec. 41:381-388.

Fávero A.C.M., Pinheiro S.R., Vasconcellos S.A., Morais Z.M., Ferreira F. \& Ferreira Neto J.S. 2002. Sorovares de leptospiras predominantes em exames sorológicos de bubalinos, ovinos, caprinos, eqüinos, suínos e cães de diversos estados brasileiros. Ciência Rural 32:613-619.

Haanwinckel M.C.S., Megid J. \& Souza L.C. 2004. Avaliação da prova de imunoperoxidase como recurso diagnóstico na leptospirose animal. Arqs Inst. Biológico, São Paulo, 71:293-301.

Hashimoto V.Y., Anzai E.K., Lima B.A.C., Silva F.G., Alves L.A., Freire R.L., Teles P.S., Garcia J.L., Muller E.E. \& Freitas J.C. 2008. Associação entre as lesões renais microscópicas e a presença de anticorpos contra Leptospira spp em suínos aparentemente sadios, abatidos em frigorífico da região norte do estado do Paraná. Semina, Ciênc. Agrárias 29:875-880.

Hamir A.N., Hanlon C.A., Niezgoda M. \& Rupprecht C.E. 2001. The prevalence of intersticial nephritis and leptospirosis in 283 raccoons (Procyon lotor) from 5 different sites in the United States. Can. Vet. J. 42: 869-871.

Langoni H., Cabral K.S.M. \& Jacobi H. 1995. Inquérito soroepidemiológico para leptospirose suína. Anais 7ํㅜㄹ Congresso Brasileiro de Veterinários Especialistas em Suínos, Blumenau, SC. 153p.

Lima P.C.R. 1996. Diagnóstico de leptospirose em suínos no Rio Grande do Sul: exames laboratoriais em fêmeas suínas descartadas em frigoríficos e em reprodutores de granjas com e sem problemas de reprodução, durante o período de um ano. Arqs Fac. Vet. UFRGS 24:119-121.

Martínez J., Segalés J., Adurez G., Atxaerandio R., Jaro P., Ortega J., Peres B. \& Corpa J.M. 2005. Pathological and aetiological studies of multifocal intersticial nephritis in wasted pigs at slaughter. Res. Vet. Sci. 81:92-98.

Miller D.A., Wilson M.A., Owen W.J. \& Beran G.W. 1990. Porcine leptospirosis in Iowa. J. Vet. Dentistry 2:171-175.

Niwetpathomwat A., Luengyosluechaku S. \& Geawduanglek S. 2006. A serological investigation of leptospirosis in sows from central Thailand. Southeast Asian J. Trop. Med. Public Hlth 37:716-719.

Oliveira S.J., Lima P.C.R., Barcellos D.E.S.N. \& Borowski S.M. 1995. Sorologia para diagnóstico de leptospirose em suínos no Rio Grande do Sul: resultados obtidos de granjas com e sem problemas de reprodução. Pesq. Agropec. Gaúcha 1:263-267.

Oliveira S.J. 1999. Nova ameaça à reprodução em suínos, além da leptospirose? Hora Vet. 19:87-90.

Ortiz A., Lorz C., Catalán P., Justo P. \& Egido J. 2000. Role and regulation of apoptotic cell death in the kidney Y2K Update. Front. in Biosci. 5:735749.

Osava C.F., Salaberry S.R.S., Nascimento C.C.N., Lima-Ribeiro A.M.C., Moreira R.Q., Castro J.R. \& Rigo V.H.B. 2010. Ocorrência de anticorpos anti-Leptospira spp. em diferentes sistemas de criação de suínos. Biosci. J. 26: 202-207.

Perea A., Garcia R., Maldonado A., Tarradas M.C., Luque I., Astorga R. \& Arenas A. 1994. Prevalence of antibodies to different Leptospira interrogans serovar in pigs on large farms. Zentralbl. Veterinärmed. B 41:12-516.

Piauí 2009. Bacia do Rio Poti. Teresina, PI. Disponível em <www.pi.gov.br/ download/Poti.pdf> Acesso em 20 jul. 2009.

Pirane C.L. 1994. Evaluation of kidney biopsy specimes, p.85-115. In: Tisher C.C. \& Brenner B.M. (Eds), Renal Pathology: With clinical and functional correlations. Vol.2. $2^{\text {nd }}$ ed. J.B. Lippincott Company, Philadelphia.

Ramos A.C.F. \& Lilenbaum W. 2002. Fatores que influenciam na ocorrência de aglutininas anti-Leptospira em suínos de criação tecnificada do Estado do Rio de Janeiro. Revta Bras. Med. Vet. 24:20-29.

Saglam Y.S., Yener Z., Temur A. \& Yalcin E. 2008. Immunohistochemical detection of leptospiral antigens in cases of naturally occurring abortions in sheep. Small Rumin. Res. 74:119-122. 
Savill J. 1994. Apoptosis and the kidney. J. Am. Soc. Nephrol. 5:12-21.

Scanziani E., Sironi G. \& Mandelli G. 1989. Immunoperoxidase studies on leptospiral nephritis of swine. Vet. Pathol. 26:442-444.

SEBRAE 2009. Aspectos Históricos. Timon, MA. Disponível em <http:// www.sebrae legal.com.br/arquivos/Historico_Timon.pdf> Acesso em 25 jun. 2009.

Shimabukuro F.H., Domingues P.F., Langoni H., Silva A.V., Pinheiro J.P. \& Padovani C.R. 2003. Pesquisa de suínos portadores renais de leptospiras pelo isolamento microbiano e reação em cadeia pela polimerase em amostras dos rins de animais sorologicamente positivos e negativos para leptospirose. Braz. J. Vet. Res. Anim. Sci. 40:243-253.

Silva F.G., Freitas J.C., Anzai E.K., Hashimoto V.Y., Giraldi N., Delbem A.C.B., Bracarense A.P.F.R.L., Reis A.C.F. \& Vasconcellos S.A. 2005. Leptospires detection in kidney, liver and uterus of cows slaughtered in Paraná state, Brasil. Braz. J. Microbiol. 36:38-42.

Sitprija V., Pipatanul V., Mertowidjojo K., Boonpuckhaving V. \& Boon- puckhaving S. 1980. Pathogenesis of renal disease in leptospirosis: Clinical and experimental studies. Kidney Intern. 17:827-36.

Sorenson C.M. 1998. Life, death and kidneys: Regulation of renal programmed cell death. Curr. Opin. Nephrol. Hypert. 7:5-12.

Soto F.R.M., Vasconcellos S.A., Pinheiro S.R., Bernarsi F. \& Camargo S.R. 2007. Artigo de revisão: Leptospirose suína. Arqs Inst. Biológico, São Paulo, 74:379-395.

Souza A.S. 2000. Estudo da prevalência de Leptospira interrogans em reprodutores suínos em produção e aspectos epidemiológicos da infecção em Goiás. Dissertação de Mestrado, Escola de Veterinária, Universidade Federal de Goiás, Goiânia, GO. 74p.

Wong V.Y., Keller P.M., Nuttall M.E. \& Kikly K. 2001. Role of caspases in human renal proximal tubular epithelial cell apoptosis. Eur. J. Pharmacol. 433: 135-140.

Yang C.W., Wu M.S. \& Pan M.J. 2001. Leptospirosis renal disease. Nephrol. Dial. Transplant. 16(S5):73-77. 